\title{
РЕЗУЛЬТАТЫ ОПЫТНО-ЭКСПЕРИМЕНТАЛЬНОЙ РАБОТЫ ПО РАЗВИТИЮ ПОЗНАВАТЕЛЬНОЙ АКТИВНОСТИ СТАРШЕКЛАССНИКОВ В ПРОЦЕССЕ ОБУЧЕНИЯ МАТЕМАТИКЕ
}

\author{
М.Ю. Шонин \\ Московский гуманитарный университет
}

\begin{abstract}
Аннотация: В статье представлены основные результаты опытно-экспериментальной работы диссертационного исследования «Развитие познавательной активности старшеклассников в проиессе обучения математике». Достоверность проведенного констатирующего и формирующего эксперимента оценивалась при помощи методов математической статистики. Положительные результаты динамики развития познавательной активности старшеклассников 8 процессе обучения математике подтверждают выдвинутую гипотезу исследования.

Ключевые слова: познавательная активность и ее существенные признаки (познавательный интерес, воля, коммуникабельность, инициативность, целеустремленность), старшеклассник, опьтно-экспериментальная работа
\end{abstract}

\section{RESULTS OF EXPERIMENTAL WORK ON THE DEVELOPMEN OF COGNITIVE ACTIVITY OF STUDENTS IN THE PROCESS OF TEACHING MATHEMATICS}

\author{
M.Yu. Shonin \\ Moscow University for the Humanities
}

\begin{abstract}
The article presents the main results of experimental work of the dissertation study «Development of cognitive activity of students in the process of training of mathematics». The validity of the ascertaining and formative experiment was assessed using methods of mathematical statistics. The positive results of the dynamics of the development of cognitive activity of students in the process of teaching mathematics support the hypothesis of the study.

Keywords: cognitive activity and its essential features (cognitive interest, will, sociability, initiative, determination), student, experimental work

Современная социальная ситуация требует от старшеклассников и выпускников проявления активной позиции в учебно-познавательной деятельности, как в школе, так и после ее окончания, в момент вступления во взрослую жизнь. Эта важнейшая педагогическая задача, поставленная перед системой образования, определила приоритет, стратегию и основные направления в исследовании и разработке приемов и методов обучения (Федеральный закон «Об образовании в Российской Федерации», 2012). При этом главной задачей учителя является «обучение как стремление помочь человеку обнаружить то, что в нем заложено» (Маралов, Ситаров, 2012: 143).

Анализ философских и психолого-педагогических исследований выявил, с одной стороны, отсутствие современного теоретико-методологического обоснования, с другой, - потребность образовательной практики в методическом обеспечении развития познавательной активности. С этой целью автором проведено диссерта-
\end{abstract}


Научные труды Московского гуманитарного университета

2020 № 4

ционное исследование «Развитие познавательной активности старшеклассников в процессе обучения: на примере математики».

В ходе теоретико-методологического анализа было сделано предположение о том, что развитие познавательной активности у старшеклассников представляет собой целенаправленный процесс стимулирования личностных качеств, характеризующих интеpec, обращенный к области познания, проявление готовности к инициативной самостоятельной или коллективной познавательной деятельности. Мобилизация умственного напряжения и волевых усилий, достижение учебно-познавательных целей будут проходить эффективнее, если рассматривать познавательную активность через совокупность существенных признаков, отражающих ее многоаспектность и междисциплинарность. Дидактическое обеспечение развития существенных признаков познавательной активности у старшеклассников в процессе обучения математике осуществляется путем научно обоснованного отбора специальных задач и комплекса дидактических приемов, позволяют построить и обосновать логику развития познавательной активности.

Методологический анализ научных понятий ориентирует исследователей и ученых на многостороннее и широкое изучение понятийно-терминологического содержания науки. Так, по мнению А.Я. Найна, сущность и содержание того или иного научного понятия выступает основой проектирования процессов его формирования или развития в структуре личности (Найн, 1995).

В этой связи, исследуемое понятие «познавательная активность» было рассмотрено с позиций различных отраслей научного знания. Использование контент-анализа позволило выделить ее существенные признаки: инициативность, познавательный интерес, коммуникабельность, волю, целеустремленность. Эффективность развития выделенных существенных признаков обусловлена грамотным выбором методологического подхода. Использование системного подхода позволило «обосновать логику развития признаков путем установления причинно-следственных зависимостей и закономерностей, внутренних взаимосвязей между ними» (Шонин, 2017: 207).

Для подтверждения сформулированных условий гипотезы требовалось проведение опытно-экспериментальной работы. Исходя из концепции настоящего исследования, его цели, гипотезы и задач, наиболее целесообразно проведение педагогического эксперимента при помощи метода контрольных и экспериментальных групп (Яковлева, 2003). Опытно-экспериментальная работа традиционно включала в себя констатирующий, формирующий и контрольный эксперименты.

Цель констатирующего эксперимента заключалась в выявлении и содержательном анализе начального уровня развития познавательной активности и ее существенных признаков. В этой связи была задействована батарея верифицированных методик. Для измерения познавательного интереса был выбран тест Е.В. Ненаховой «Диагностика уровня развития познавательного интереса» (Ненахова, 2014); для определения инициативности была использована модифицированная шкала Н.Б. Стамбуловой «Самооценка степени проявления личностью инициативы» (Ильин, 2008); для измерения коммуникабельности была задействована шкала 
Н.Д. Твороговой «Техника общения» (Творогова, 2002); для диагностирования воли был использован модифицированный опросник Е.П. Ильина и Е.К. Фещенко «Определение уровня развития воли» (Фещенко, 1999); для измерения целеустремленности была использована модифицированная шкала Н.Б. Стамбуловой «Самооценка степени проявления личностью целеустремленности» (Ильин, 2008). Измерение уровня развития познавательной активности осуществлялось при помощи методики Ч. Спилберга «Оценка уровня познавательной активности» (Спилберг, 1987).

Проведенный констатирующий эксперимент позволил установить:

1. Низкие уровни развития существенных признаков познавательной активности, выражение которых нашло отражение в позициях опросников. Во-первых, познавательный интерес - отсутствие позитивного отношения к предмету математики, непонимание прикладного характера математических знаний. Во-вторых, инициативность - склонности старшеклассников к осуществлению деятельности «по образцу», нежеланием приобщиться к самостоятельной и творческой познавательной деятельности в процессе обучения. В-третьих, коммуникабельность - несформированность личностных качеств, отражающих умения и навыки социального взаимодействия: установление контактов со сверстниками, конструктивное и взаимообогащающее общение с окружающими. В-четвертых, воля - эмоциональные переживания, связанные с неуверенностью в возможности решить поставленную учителем ту или иную задачу. В-пятых, целеустремленность - отсутствие умений и навыков постановки цели, формулировки задач, позволяющих ее решить, проведения анализа полученных результатов на соответствие поставленной цели).

2. Незначимость различий в распределении полученных баллов старшеклассниками контрольной и экспериментальной групп, что свидетельствует о схожих уровнях развития познавательной активности и ее существенных признаках.

3. Прямые и сильные парные связи между выделенными признаками и познавательной активностью $\quad\left(r_{x y}^{1}=0,83 ; r_{x y}^{2}=0,85 ; r_{x y}^{3}=0,89 ; r_{x y}^{4}=0,9\right)$. Значения коэффициентов детерминации каждой из связей $\left(R_{1}^{2}=0,69 ; R_{2}^{2}=0,72 ; R_{3}^{2}=0,79 ; R_{4}^{2}=0,71 ; R_{5}^{2}=0,81\right)$ позволяют прийти к выводу о высокой степени влияния каждого признака на развитие познавательной активности.

4. Прямые и сильные парные связи между выделенными признаками, выстроенные в логике развития познавательной активности $\left(r_{x y}^{1}=0,915 ; r_{x y}^{2}=0,934 ; r_{x y}^{3}=0,85 ; r_{x y}^{4}=0,874\right)$.

Полученные данные стали исходными для проведения формирующего эксперимента, целью которого являлись отбор и интегрирование специальных задач и дидактических приемов в процессе обучения математике в соответствии с логикой развития познавательной активности.

Формирующий эксперимент осуществлялся в течение учебного года (20182019 гг.) и предусматривал активное использование в процессе обучения математике научно обоснованного дидактического обеспечения, стимулирующего развитие выделенных существенных признаков: 
Научные труды Московского гуманитарного университета

2020 № 4

- познавательный интерес: задачи с историческим и практическим содержаниями (Гаврилычева 2016; Шапиро, 1990), приемы: создание проблемных ситуаций (Мадера, 2003), насыщение содержания урока историческим знанием (Дюрягина, Чикунова, 2010);

- инициативность: задачи с избыточными или противоречивыми данными (Аммосова, Коваленко, 2015), задачи с неопределенным окончанием (Маралов, Ситаров, 1990), приемы: намеренных ошибок (Там же), составление задач с практическим содержанием (Там же), создание ситуаций, при которых обучающийся вынужден задавать вопросы типа: «Почему так решается данная задача?» (Там же);

- коммуникабельность: задачи на готовых чертежах (Доброва, 2016; Ланда, 1966), прием объединения усилий обучающихся достижении учебных целей (Маралов, Ситаров, 1990);

- воля: (задачи государственного экзамена (Баканов, 1979), приемы: свободного выбора тематической задачи (Выготский, 1991), наставления и косвенного одобрения (Селиванов, 1974), постепенного повышения уровня сложности тематических задач (Калин, Панченко, 1980; Бабаев, Кулагина, Шкитина, 2005);

- целеустремленность: задачи на определение информационного поля, предмет и научную новизну (Костаева, 2008), прием постепенно убывающей педагогической помощи (Смирнова, 1998).

Следует особо подчеркнуть, что предложенное экспериментальное обеспечение не определяло основу обучения, а органично дополняло ее.

После проведения формирующего эксперимента была произведена повторная диагностика выявления уровней развития существенных признаков познавательной активности, результаты которой представлены в таблице 1.

Таблица 1

\section{Результаты диагностики развития признаков познавательной активности у старшеклассников в контрольной и экспериментальной группах (контрольный эксперимент)}

\begin{tabular}{|l|c|c|c|c|c|c|}
\hline \multirow{2}{*}{$\begin{array}{l}\text { Существенные признаки } \\
\text { познавательной активности }\end{array}$} & \multicolumn{2}{|c|}{ Низкий уровень } & \multicolumn{2}{c|}{ Средний уровень } & \multicolumn{2}{c|}{ Высокий уровень } \\
\cline { 2 - 7 } & К & $Э$ & К & Э & К & Э \\
\hline $\begin{array}{l}\text { Познавательный интерес, } \\
\text { чел. (\%) }\end{array}$ & $\begin{array}{c}41 \\
(68,3 \%)\end{array}$ & $\begin{array}{c}14 \\
(23,3 \%)\end{array}$ & $\begin{array}{c}19 \\
(31,7 \%)\end{array}$ & $\begin{array}{c}41 \\
(68,3 \%)\end{array}$ & $\begin{array}{c}0 \\
(0 \%)\end{array}$ & $\begin{array}{c}5 \\
(8,3 \%)\end{array}$ \\
\hline Инициативность, чел. (\%) & $\begin{array}{c}49 \\
(81,6 \%)\end{array}$ & $\begin{array}{c}22 \\
(36,7 \%)\end{array}$ & $\begin{array}{c}11 \\
(18,3 \%)\end{array}$ & $\begin{array}{c}31 \\
(51,7 \%)\end{array}$ & $\begin{array}{c}0 \\
(0 \%)\end{array}$ & $\begin{array}{c}7 \\
(11,7 \%)\end{array}$ \\
\hline Коммуникабельность, чел. (\%) & $\begin{array}{c}36 \\
(60 \%)\end{array}$ & $\begin{array}{c}11 \\
(18,3 \%)\end{array}$ & $\begin{array}{c}24 \\
(40 \%)\end{array}$ & $\begin{array}{c}39 \\
(65 \%)\end{array}$ & $\begin{array}{c}0 \\
(0 \%)\end{array}$ & $\begin{array}{c}10 \\
(16,7 \%)\end{array}$ \\
\hline Воля, чел. (\%) & $\begin{array}{c}24 \\
(40 \%)\end{array}$ & $\begin{array}{c}6 \\
(10 \%)\end{array}$ & $\begin{array}{c}35 \\
(58,3 \%)\end{array}$ & $\begin{array}{c}25 \\
(41,7 \%)\end{array}$ & $\begin{array}{c}1 \\
(1,7 \%)\end{array}$ & $\begin{array}{c}29 \\
(48,3 \%)\end{array}$ \\
\hline Целеустремленность, чел. (\%) & $\begin{array}{c}39 \\
(65 \%)\end{array}$ & $\begin{array}{c}13 \\
(21,6 \%)\end{array}$ & $\begin{array}{c}21 \\
(35 \%)\end{array}$ & $\begin{array}{c}40 \\
(66,7 \%)\end{array}$ & $\begin{array}{c}0 \\
(0 \%)\end{array}$ & $\begin{array}{c}7 \\
(11,7 \%)\end{array}$ \\
\hline
\end{tabular}


Научные труды Московского гуманитарного университета

2020 № 4

Выявленная существенная разница в уровнях их развития признаков не случайна и объясняется содержательными изменениями, которые были отражены в анкетах респондентов:

1. Число респондентов экспериментальной группы с положительным настроем к изучению математики увеличилось на 35 человек, т.е. на 58,3 \%. Вместе с тем, в контрольной группе на момент завершения формирующего эксперимента существенных изменений не выявлено. Так, число респондентов, у которых изучение математики вызывает позитивные эмоции, увеличилось только на 4 человека, т.е. на 6,7 \%.

2. Большинство респондентов экспериментальной группы в ходе обучения математики стали проявлять самостоятельный поиск, направленный на решение познавательных задач - 48 человек, т.е. 80 \% обучающихся с приращением на 46 человек, т.е. 76,7\%. И только 7 старшеклассников в контрольной группе, т.е. 11,7 \% разделяют точку зрения большинства обучающихся экспериментальной группы.

3. Около половины респондентов экспериментальной группы - 34 человека, или 56,7 \% проявляют интерес к составлению и решению собственных математических задач, тогда как на момент начала формирующего эксперимента их число составляло - 2 человека или $3,3 \%$.

4. В процессе изучения математики респонденты экспериментальной группы активно используют дополнительную литературу - 42 обучающихся, т.е. $35 \%$, тогда как в контрольной группе результат остался на уровне 5 человек, т.е. 4,2 \% .

5. Число старшеклассников, активно участвующих в конструктивных дискуссиях по теме урока, точно и ясно излагающих свою позицию в обсуждаемом вопросе в экспериментальной группе составило 47 человек (78,3\%), тогда как на этапе первичной диагностики всего лишь - 19 (31,7 \%) старшеклассников. При этом обучающиеся контрольной группы отличились, схожими с результатами констатирующего эксперимента, числовыми показателями - 21 (35 \%) респондент.

6. Большинство респондентов экспериментальной группы продемонстрировали умение самостоятельно разбираться в условии, построении модели решения и реализации сложной математической задачи - 38 обучающихся, т.е. 63,3\%. По мере проведения эксперимента старшеклассники с большим энтузиазмом старались решать сложные математические задачи. Это выражалось в желании продолжать решать задачу, как на перемене между уроками, так и дома, самостоятельно. В контрольной группе существенных изменений не зафиксировано.

7. Проведение учебно-исследовательских работ позволило развить у респондентов экспериментальной группы умения планировать свою деятельность (4676,7 \% старшеклассников), выражающиеся в навыках формулирования постановки цели, формулировании конкретных задач для ее достижения, анализа и интерпретации результатов исследования (42-70 \% старшеклассника). В контрольной группе изменений не выявлено.

Результаты, заслуживающие особый интерес, были получены в процессе анкетирования по методике Ч. Спилберга (рис. 1). 


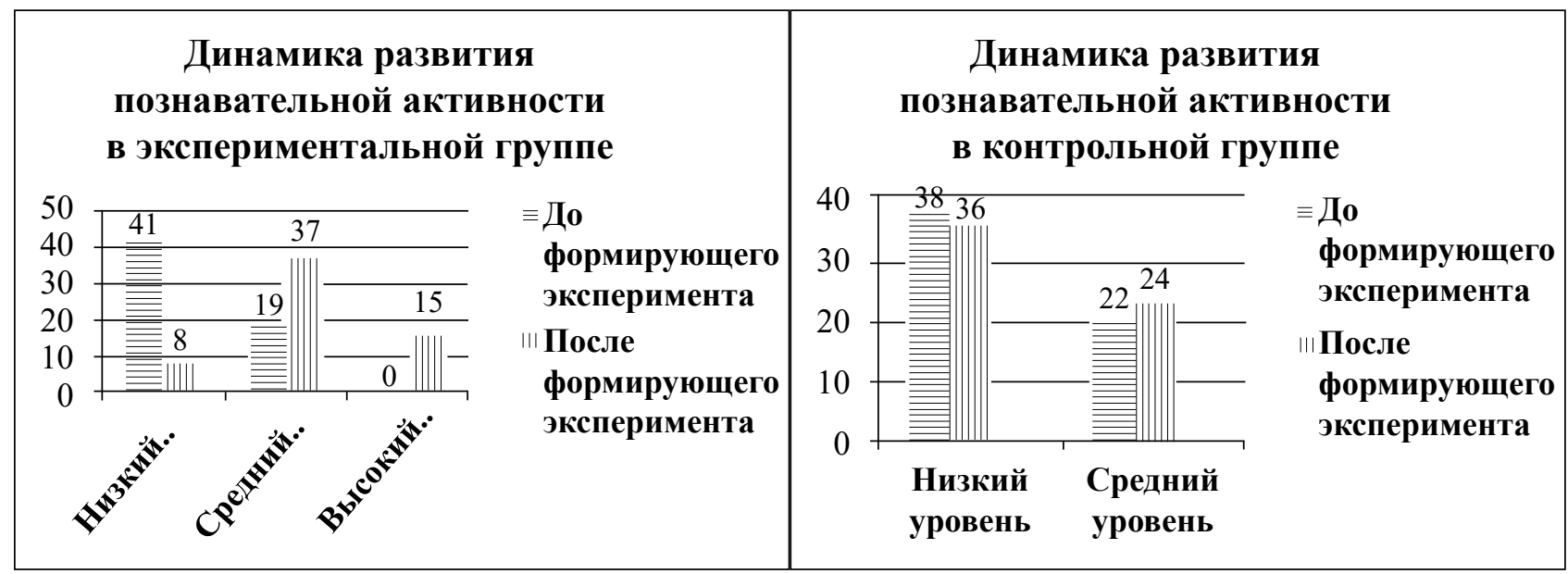

Рисунок 1. Сравнение результатов развития познавательной активности у респондентов экспериментальной и контрольной групп до и после проведения формирующего эксперимента

Так, в контрольной группе до и после проведения эксперимента выявились незначительные изменения - доля респондентов с низким уровнем развития познавательной активности уменьшилась на 0,3\% (2 ученика), при этом старшеклассники с высоким уровнем установлены не были. Вместе с тем отмечалась положительная динамика развития познавательной активности у обучающихся экспериментальной группы, которая выразилась в существенном сокращении количества респондентов с низким уровнем на 55 \% (33 старшеклассника), увеличении числа испытуемых на высоком уровне - 25 \% (15 обучающихся).

Для обработки результатов был задействован $\mathrm{U}_{\ni}$ - критерий Манна-Уитни. Эмпирические значения критерия $U_{\text {э }}$ равны 24,$5 ; 37,5 ; 54,5$ при табличных значениях $138 ; 102 ; 180$ для 9-х, 10-х и 11-х классах соответственно на уровне значимости $\mathrm{p}=$ 0,05 вследствие чего можно констатировать, что положительная динамика повышения уровня развития познавательной активностью неслучайна и обусловлена проведенной опытно-экспериментальной работой.

Таким образом, выявленная положительная динамика и результаты статистической обработки по примененным критериям свидетельствуют о достоверности гипотезы развития познавательной активности у старшеклассников в процессе обучения математике.

\section{СПИСОК ЛИТЕРАТУРЫ}

Аммосова, Н.В., Коваленко, Б.Б. (2015) Решение задач по математике с избыточными или противоречивыми данными в общеобразовательной школе //Успехи современного естествознания. № 5. С. 183-185.

Бабаев, В.С., Кулагина, М.В., Шкитина, Ю.Ю. (2005) Определение трудности и сложности физических задач //Физическое образование в вузах. Т. 1. № 4. С. 93-101.

Баканов, Е.Н. (1979) Исследование генезиса волевого действия: Дисс. ... канд. псих. наук. / Е.Н. Баканов. М., 173 с. 
Выготский, Л.С. (1991) Педагогическая психология. М.: Педагогика, 480 с.

Гаврилычева, М.Г. (2016) Проблемы обучения математике студентов гуманитарных направлений //Вестник Московской международной академии. № 1. C. $174-177$.

Доброва, Н.В. (2016) Решение задач по готовым чертежам - одно из эффективных средств усвоения и закрепления теоретического материала по геометрии // Символ науки. № 7. С. 10-12.

Дюрягина, Е.В., Чикунова, О.И. (2010) Задачи с историческим содержанием как средство развития познавательного интереса школьников к математике //Международный журнал экспериментального образования. № 8. С. 79-80.

Ильин, Е.П. (2009) Психология воли. 2-е изд. СПб.: Питер. С. 141.

Калин, В.К., Панченко, В.И. (1980) Изучение волевой активности школьников в связи с особенностями их продуктивного мышления //Вопросы психологии, Т.10, № 2. С. 93-99.

Костаева, Т.В. (2008) Формирование устойчивого учебно-познавательного интереса школьников в процессе их профессионально-личностного самоопределения: автореф. ... канд. пед. наук / Т.В. Костаева. М., 24 с.

Ланда, Л.Н. (1966) Алгоритмизация в обучении. М.: Просвещение. 522 с.

Мадера, А.Г. (2003) Математические софизмы: Правдоподобные рассуждения, приводящие к ошибочным утверждениям: Кн. для учащихся 7-11 кл. / А.Г. Мадера, Д.А. Мадера. М.: Просвещение. 112 с.

Маралов, В.Г., Ситаров, В.А. (2012) Педагогика и психология ненасилия в образовании. М.: Юрайт. 424 с.

Найн, А.Я. (1995) О методологическом аппарате диссертационных исследований //Педагогика. № 5. С. 44-49.

Ненахова, Е.В. (2014) Диагностика познавательного интереса у обучающихся старших классов средней общеобразовательной школы //Наука и школа. №1. C. $207-211$.

Селиванов, В.И. (1974) Психология волевой активности. Рязань: Рязан. пед. инта, $150 \mathrm{c}$.

Ситаров, В.А., Маралов, В.Г. (1990) Развитие инициативы школьников как фактор демократизации учебно-воспитательного процесса: сборник статей под ред. В.А. Сластенина. М.: МГПИ им. В.И. Ленина, С. 99-109.

Смирнова, И.Ф. (1998) Педагогические условия становления жизненных целей старшеклассников: Дисс. ... канд. пед. наук. / И.Ф. Смирнова. Пенза, 203 с.

Спилберг, Ч.Д. (1987) Оценка уровня познавательной активности / Спилберг Ч.Д. М.: Просвещение, 116 с.

Творогова, Н.Д. (2002) Общение: диагностика и управление. М., 246 с.

Федеральный закон от 29 декабря 2012 г. №273/Ф3 «Об образовании в Российской Федерации» [Электронный ресурс] // КонсультантПлюс. URL: http://www. consultant.ru/document/cons_doc_LAW_140174/ (Дата обращения: 18.07.2020). 
Фещенко, Е.К. (1999) Возрастно-половые особенности самооценки волевых качеств: Автореф. дисс... канд. наук. / Е.К. Фещенко. СПб, 15 с.

Шапиро, И.М. (1990) Использование задач с практическим содержанием в преподавании математики. М.: Просвещение. 95 с.

Шонин, М.Ю. (2017) Развитие познавательной активности учащихся на основе системного подхода // Вестник Череповецкого государственного университета. № 6 (81). C. 205-210.

Яковлева, Н.О. (2003) Педагогическое проектирование инновационных систем: Дисс. ... д-ра пед. наук. / Н.О. Яковлева. Челябинск, 355 с.

Шонин Максим Юрьевич - аспирант кафедры педагогики и психологии высшей школы Московского гуманитарного университета. Научный руководитель - д-р пед. н., проф. В.А. Ситаров. Адрес: 111395, Россия, г. Москва, ул. Юности, д. 5. Тел. +7 (915) 406-89-76. Эл. адрес: st_max_92@mail.ru.

Shonin Maksim Yurievich, Postgraduate Student, Department of Pedagogy and Psychology of Higher School, Moscow University for the Humanities. Scientific Adviser V.A. Sitarov, Doctor of Pedagogy, Professor. Postal address: 5, Yunosti St., Moscow, Russian Federation 111395. Tel.: +7 (915) 406-89-76. E-mail: st_max_92@mail.ru.

\section{Для цитирования:}

Шонин М.Ю. Результаты опытно-экспериментальной работы по развитию познавательной активности старшеклассников в процессе обучения математике // Научные труды Московского гуманитарного университета. 2020. №4. C. 48-55. DOI: https://www.doi.org/ 10.17805/trudy.2020.4.7 